(year 1) and $85.4 \%$ (year 2), (insufficient number of cases to assess persistence at year 3 or further). As second biological drug, it was $89.8 \%$ (year 1), 75.2\% (year 2), $67.4 \%$ (year 3 ) and $59.2 \%$ (year 4 ) and as third biological drug the figures were, respectively, $69.6 \%, 58.4 \%, 54.5 \%$ and $46.1 \%$. Cox-regression analysis (table 1) showed that the probability of persistence on GOL therapy was higher in first vs second or third biological line patients (Hazard Ratio for discontinuation [HR]: 2.30 [95\% Cl: 1.16-4.55] for second and 3.92 [2.07-7.39] for third line), and in patients with concomitant MTX (HR discontinuation=0.55 [0.33-0.91]), and lower in those needing CS (HR discontinuation=2.83 [1.72-4.66]).

Abstract AB1332 - Table 1. Factors related to persistence of golimumab treatment

\begin{tabular}{|c|c|c|c|}
\hline & Hazard Ratio of Discontinuation & $95 \%$ Confidence Interval & p \\
\hline \multicolumn{4}{|l|}{ Initial Model } \\
\hline Gender (women vs men) & 1.23 & $(0.62-2.44)$ & 0.56 \\
\hline Age at golimumab initiation & 1.01 & $(0.99-1.04)$ & 0.25 \\
\hline Disease duration & 0.99 & $(0.96-1.02)$ & 0.38 \\
\hline Smoking habit & 1.67 & $(0.85-3.26)$ & 0.13 \\
\hline Overweight (vs normal) & 1.61 & $(0.74-3.52)$ & 0.23 \\
\hline Obesity (vs normal) & 1.53 & $(0.64-3.66)$ & 0.33 \\
\hline Second vs first biological drug & 3.06 & $(1.28-7.32)$ & 0.01 \\
\hline Third vs first biological drug & 5.22 & $(2.18-12.49)$ & $<0.01$ \\
\hline Axial SpA vs RA & 0.79 & $(0.36-1.73)$ & 0.55 \\
\hline PsAvs RA & 0.59 & $(0.27-1.29)$ & 0.19 \\
\hline Methotrexate & 0.41 & $(0.21-0.80)$ & 0.01 \\
\hline Steroids & 4.26 & $(2.26-8.04)$ & $<0.01$ \\
\hline \multicolumn{4}{|l|}{ Final Model } \\
\hline Gender (women vs men) & 1.38 & $(0.84-2.27)$ & 0.21 \\
\hline Age at golimumab initiation & 1.01 & $(1.00-1.03)$ & 0.14 \\
\hline Second vs first biological drug & 2.30 & $(1.16-4.55)$ & 0.02 \\
\hline Third vs first biological drug & 3.92 & $(2.07-7.39)$ & $<0.01$ \\
\hline \begin{tabular}{|l} 
Methotrexate \\
\end{tabular} & 0.55 & $(0.33-0.91)$ & 0.02 \\
\hline Steroids & 2.83 & $(1.72-4.66)$ & $<0.01$ \\
\hline
\end{tabular}

Conclusions: In patients with RA, axial SpA or PsA, the probability of persistence on GOL after initiation was high. The retention rate was higher both in patients with GOL as first biological drug and in those with concomitant therapy with MTX, and lower in those needing CS.

Acknowledgements: This study was funded by Merck Sharp and Dohme of Spain

Disclosure of Interest: None declared

DOI: 10.1136/annrheumdis-2018-eular.4577

\section{AB1333 RETENTION RATES OF ADALIMUMAB, ETANERCEPT, AND INFLIXIMAB AS BIOTHERAPIES FOR RHEUMATOID ARTHRITIS, SPONDYLOARTHRITIS, OR PSORIATIC ARTHRITIS PATIENTS IN DAILY PRACTICE IN AUVERGNE (FRANCE)}

M. Soubrier ${ }^{1}$, A. Fan ${ }^{1}$, M. Couderc ${ }^{1}$, S. Malochet-Guinamand ${ }^{1}$, S. Mathieu ${ }^{1}$, C. Giraud ${ }^{1}$, A. Tournadre ${ }^{1}$, J.-J. Dubost ${ }^{1}$, B. Pereira ${ }^{2} .{ }^{1}$ Rheumatology department, ${ }^{2}$ Biostatistics Unit, CHU Clermont-Ferrand, Clermont-Ferrand, France

Background: The use of TNF- $\alpha$ inhibitors, has considerably improved the treatment of rheumatoid arthritis (RA), spondyloarthritis ( $\mathrm{SpA})$, and psoriatic arthritis (PsA). The most widely used anti-TNFs are infliximab (IFX), adalimumab (ADA) and etanercept (ETN). Their efficacy and safety have been demonstrated in randomised controlled trials, though of short duration and involving a selected patient population differing from those seen in daily practice.

Objectives: To compare, in real-life settings, the retention rates of anti-TNF treatments (ETN, ADA, or IFX) initiated as first-line biotherapy following their approval in the three clinical indications.

Methods: Monocentre retrospective cohort involving patients on initial anti-TNF therapy for RA, SpA, or PsA since 2006.

Results: Anti-TNF treatment was initiated on 228 RA (ETN 160, ADA 45, or IFX 23), 208 SpA (ETN 91, ADA 62, or IFX 55), and 81 PsA (ETN 40, ADA 26, or IFX 15) patients. Treatment retention rates at 1,3 , and 5 years were $82 \%, 53 \%$, and $44 \%$ in $\mathrm{PR} ; 75 \%, 57 \%$, and $49 \%$ in SpA; $75 \%, 64 \%$, and $51 \%$ in PsA, with no differences detected among the pathologies $(p=0.96)$. Retention rates at 1,3 , and 5 years did not differ among the 3 anti-TNFs either for all pathologies included (ETN: $80 \%, 57 \%$, and $43 \%$; ADA: $80 \%, 58 \%$, and $51 \%$; IFX $72 \%, 56 \%$, and $52 \%$; $\mathrm{p}=0.75$ ) or each pathology alone (RA: ETN: $83 \%, 55 \%$, and $41 \%$; ADA: $83 \%$, $51 \%$, and $51 \%$; IFX: $76 \%, 44 \%$, and $44 \%, p=0.84$; SpA: ETN: $78 \%, 57 \%$, and 48\%; ADA: $78 \%, 59 \%$, and $46 \%$; IFX: $68 \%, 55 \%$, and $52 \%, p=0.81$; PsA: ETN: $70 \%, 60 \%$, and $36 \%$; ADA: $79 \%, 69 \%$, and $69 \%$; IFX: $80 \%, 66 \%$, and $53 \%$, $\mathrm{p}=0.65)$. Overall, $89 \mathrm{RA}, 85 \mathrm{SpA}$, and $28 \mathrm{PsA}$ patients discontinued treatment for inefficacy (32\%) or side effects (SE, 9\%)). In RA, predictors for treatment discontinuation were: Disease activity (DAS 28 ESR HR: 1.27 [1.05-1.55]; DAS28-CRP HR: 1.27 [1.03-1.60]), (CRP HR: 1.01 [1.01-1.02]), and corticosteroid intake (HR: 2.05 [1.027-3.32]). Concomitant methotrexate intake tended to decrease the treatment discontinuation risk (HR: 0.64 [0.41-1.01)]. Predictors for treatment discontinuation due to inefficacy were similar (DAS28 ESR, HR: 1.31 [1.05-1.63] DAS28 CRP, HR: 1.33 [1.04-1.72], CRP HR: 1.02 [1.01-1.03]), corticosteroid intake HR: 3.79 [2.02-7.11]). We were unable to identify any predictors for treatment discontinuation due to SE, though corticosteroid intake was found to be pro tective (HR: 0.23 [0.07-0.71]). In SpA, the sole predictor for treatment discontinuation identified was increased BASDAI score (HR: 1.02 [1.01-1.04]) while the sole predictor for treatment maintenance was inflammatory syndrome (CRP HR: 0.97 [0.95-0.99]. Similar findings were seen for treatment discontinuation due to inefficacy (BASDAI HR: 1.03 [1.01-1.05)]; CRP HR: 0.98 [0.96-0.99]) We were unable to identify any predictors for treatment discontinuation due to SE In PsA, active smoking was revealed to be a predictor for treatment discontinuation due to inefficacy (HR: 2.234 [1.02-4.91)]

Conclusions: ETN, ADA, and IFX display similar treatment retention rates in RA $\mathrm{SpA}$, or PsA without between-agent differences.

Disclosure of Interest: None declared

DOI: 10.1136/annrheumdis-2018-eular.5086

\section{AB1334 EVALUATION OF DYNAMICS OF MORTALITY FROM DISEASES OF THE BONE-MUSCULAR SYSTEM IN KARAKALPAKSTAN}

M. Salokhiddinov, U. Anarmetova, G. Haydarova. TASHKENT MEDICA ACADEMY, Tashkent, Uzbekistan

Background: Karakalpakstan is now mostly desert and is located in western Uzbekistan near the Aral Sea, in the lowest part of the Amu Darya basin. The desertification of the Aral Sea has brought a lot of dust in the air, and respiratory diseases - bone-muscular diseases - have become the largest local health problem among the population of Karakalpakstan, a region in the North Western part of Uzbekistan.

Objectives: To asses of the dynamics of mortality trends from diseases of bonemuscular system (BMS) in the Karakalpakstan region in 2010-2015

Methods: To study mortality from BMS, databases on mortality of residents in Karakalpakstan for 2010-2015, obtained with the help of an automated mortality registration system, were used to automatically code and select the original cause of death in accordance with the rules of ICD-10.

Results: In the Karakalpakstan region, there has been a trend of a significant increase in mortality from BMS from 3.0 in 2010 to 5.6 per 100000 in 2015 (1.9 times), with a slight decrease in the death rate from the BMS in Uzbekistan from 1.7 in 2010 to 1.6 in 2015 per 100 thousand people (the rate of decline is $5.9 \%$ ). So that Decrease in the mortality rate from diseases of the musculoskeletal system in Uzbekistan from 1.7 to 1.6 per 100 thousand of population (the rate of decrease is $5.9 \%$ ) and the growth of mortality rates from diseases of the muscu loskeletal system was 1.9 times from 2001 to 2015

Conclusions: The growth of mortality rates from musculoskeletal system dis eases in the Karakalpakstan region is not related to the rates of overall mortality of the population, but is more reliable due to the use of the automated system for recording mortality, as well as training physicians to codify medical and statistical diagnoses.

\section{REFERENCES :}

[1] Wolfe F, Michaud K, Gefeller O, et al. Predicting mortality in patients with rheumatoid arthritis. Arthritis \& Rheumatism. 2003;48(6):1530-1542

[2] Wolfe F, Ross K, Hawley DJ, et al. The prognosis of rheumatoid arthritis and undifferentiated polyarthritis syndrome in the clinic: a study of 1141 patients. Journal of Rheumatology 1993;20(12):2005-2009.

Disclosure of Interest: None declared

DOI: 10.1136/annrheumdis-2018-eular.2152

\section{AB1335 SERUM MMP-3 IS CLOSELY RELATED TO KNEE JOINT SYMPTOMS IN RHEUMATOID ARTHRITIS PATIENTS: A CROSS-SECTIONAL STUDY FROM KURAMA COHORT}

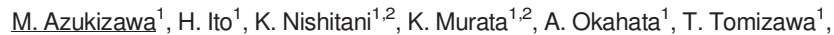
M. Hashimoto ${ }^{2}$, M. Tanaka ${ }^{2}$, T. Mimori ${ }^{3}$, S. Matsuda ${ }^{1} .{ }^{1}$ Department of Orthopaedic Surgery; ${ }^{2}$ Department of Advanced Medicine for Rheumatic Diseases;

${ }^{3}$ Department of Rheumatology and Clinical Immunology, Kyoto University Graduate School of Medicine, Kyoto, Japan

Background: Joint damage progression occurs within the first 2 years of rheumatoid arthritis (RA). ${ }^{1}$ Large joints are often involved in RA patients. The knee joint, in particular, is affected in about $30 \%$ of RA patients. ${ }^{2}$ Knee joint disability in RA is thought to be one of the most important prognostic factors decreasing quality of life. However, few studies have focused on what would influence knee joint function in RA patients. Therefore, a cross-sectional study on this subject was 